\title{
Online Ordering Systems and Consumer Acceptance - Using Box Lunch Order Systems as a Case Study
}

\author{
Ling-Hui Yang ${ }^{1}$, Ting-Sheng Weng ${ }^{2}$ \& Hsiang-Pang $\mathrm{He}^{3}$ \\ ${ }^{1}$ Department of Food and Beverage Management, Tatung Institute of Commerce and Technology, Chiayi County, \\ Taiwan \\ 2 Department of Business Administration, National Chiayi University, Chiayi County, Taiwan \\ ${ }^{3}$ Department of Exercise and Health Promotion, Chung Chou University of Science \& Technology, Changhua \\ County, Taiwan
}

Correspondence: Ting-Sheng Weng, Department of Business Administration, National Chiayi University, No.580, Sinmin Rd, Chiayi City 60054, Taiwan (R.O.C.). Tel: 886-5-273-2835. E-mail: politeweng@yahoo.com.tw

Received: May 24, 2012 Accepted: June 18, 2012 Online Published: September 16, 2012

doi:10.5539/ijbm.v7n18p26 URL: http://dx.doi.org/10.5539/ijbm.v7n18p26

\begin{abstract}
Fresh food is approaching a professional food value orientation. Taiwanese people have become increasingly concerned with nutrition when eating out, and have begun to consider the nutrients and calories in box lunches, in addition to price and taste. This study constructed a platform for an online box lunch ordering system. The system contained a screen that allowed consumers to use checkboxes to select the dishes they wanted, which could then be used to calculate the nutritional information, calories, and prices of the meal combination, in order to achieve customization. At the same time, this study used purposive sampling to conduct a survey on actual online users regarding the box lunch ordering system. The measuring tool was developed based on the technology acceptance model (TAM). The linear structure equation was used to confirm the correlations between the dimensions of the TAM. The results showed that the users' perceived ease of use on the box lunch ordering system would significantly influence the perceived usefulness, which would directly influence usage attitudes. However, usefulness does not have a significant influence on usage behavioral intentions. The concept of food value will promote the development of agricultural business opportunities for local food materials.
\end{abstract}

Keywords: food value, business opportunities, technology acceptance model, box lunch website, structure equation models

\section{Introduction}

Since 7-Eleven began selling box lunches in Taiwan, it has sold over 60 million of them (Freshnet, 2009), making it the most representative product of the company, and this has created a new focus on box lunches. Regional fresh food box lunch has a professional orientation of "food value", and can promote the development of agricultural business opportunities for local food materials.

With economic development, changes in social structures, and evolution in lifestyles, eating out has gradually taken a larger share of people's food budgets. According to data from a family income and expenditure survey in Taiwan, on average, the ratio of dining out costs to food costs increased from $24.9 \%$ in 1997 to $31 \%$ in 2003 , indicating that eating out was a non-daily behavior in the past, but it has become an indispensable part of daily life (Directorate-General of Budget, Accounting and Statistics, Taiwan Executive Yuan, 2004).

Because of busy modern life, a large number of people now dine out. Other than the few who bring their own meals from home, most people choose have lunch at restaurants or choose box lunches. Since box lunches are cheap, delicious, and convenient, they are preferred by civil servants, teachers, businesspeople, students, and laborers (Li \& Chiang, 1982). People who eat out tend to eat box lunches the most. However, in order to maintain good nutrition, it is necessary to be concerned with matching diverse foods.

According to statistics from the Taiwan's Department of Health of the Executive Yuan in 2011, there were approximately $17,700,000$ daily instances of people eating out, and there were approximately six million instances of people eating out for each meal. More than $70 \% \sim 80 \%$ of office workers ate out twice a day. Dining businesses do all they can to pursue business opportunities, but they often overlook the needs for healthful food 
in the pursuit of convenience and taste. There is a high ratio of people in Taiwan who eat out. More than $20 \%$ do not have a habit of eating balanced meals, and more than $70 \%$ do not have fixed meal times. Also, restaurants emphasize spices and tend to have use fat and salt. There are many high calorie traps, such as having too much meat but few rice and vegetables; these are all common problems in dining out.

Recently, Taiwanese people have become more concerned with the concept of health and nutrition when dining out, and they have begun to be concerned with nutritional content and calories in addition to price and taste. Consumers see the selection of food as choices between health, taste, and convenience (Costa, Schoolmeester, Dekker and Jongen, 2007). This study created a box lunch ordering system, in which main feature was that it showed the real-time recipes with actual picture presented on the website, allowing the customers to understand the real-time food offerings. They could also easily click to choose the dishes they wanted, and at the same time, the system would calculate the calories and prices of the food combinations, in order to achieve customization. This study used TAM as the theoretical basis to confirm the influence of this box lunch ordering system on consumer purchase intention and consumption behavior.

The mostwell-known models investigating resistance to new technologies in the workplace was developed by Davis (1989) in the technology acceptance model (TAM). Technology Acceptance Model (TAM) had been used by many researchers to explain adoption of new systems and other information technologies in lots fields. Wu, Chu and Fang (2008) used TAM to investgate the perceived usefulness and perceived ease-of-use of the website. Hsu, Wu, Chen and Chang(2012) found that perceived quality of e-shopping, which was categorized into perceived information, perceived system, and perceived service quality, has a significant and positive influence on perceived usefulness and ease of use, and, both e-satisfaction and flow were seen to significantly influence e-loyalty on a positive level. Based on the findings, managerial implications are discussed in this paper and directions for future research are also highlighted.

This study constructed an online box lunch ordering system that could provide the nutritional components, caloric and price calculations as the research platform, and used the two dimensions of perceived usefulness and perceived ease of use in the TAM to explore the influence on usage attitudes and usage behavioral intentions regarding an ordering system that could provide related health information. This research has two purposes: 1) to understand the influence of consumer perceived usefulness and perceived ease of use on ordering system usage attitudes; and 2) to understand the influence of user usage attitudes on ordering system usage behavioral intentions.

\section{Literature Review}

\subsection{Technology Acceptance Model}

Technology acceptance model (TAM) was constructed by Davis (1989), based on the theory of reasoned action (TRA). It is used to construct a user behavioral model of their acceptance of information technology. TAM places the user at the center, and uses research to learn how users accept technology products and how their attitudes affect usage behavioral intentions for the technology products. Attitude refers to a relatively long orientation toward certain people, events, and objects, and includes the three dimensions of cognition, affection, and behavior (Chang, 2011).

TAM believes that user attitudes about information technology will be affected by their perceptions of the technology. The two factors that affect attitudes are the perceived usefulness and the perceived ease of use. Perceived usefulness refers to the users perceiving that the technology is useful, and that it can increase work efficiency. Perceived ease of use refers to the user perceiving that the system is easy to use. If the degree of the perceived ease of use is high, then the degree of the perceived usefulness will also be high and will enhance the usage attitudes. In addition, the model also includes external variables, which refer to other factors that may affect potential users to adopt the system, such as the users' personal variables, system characteristics, and environmental variables. These external variables will affect the users' perceived beliefs through the perceived usefulness and the perceived ease of use (Venkatesh \& Davis, 1996; Igbaria, et al., 1995; Szajna, 1996).

The primary theoretical models of TAM are as shown in Figure 1: 


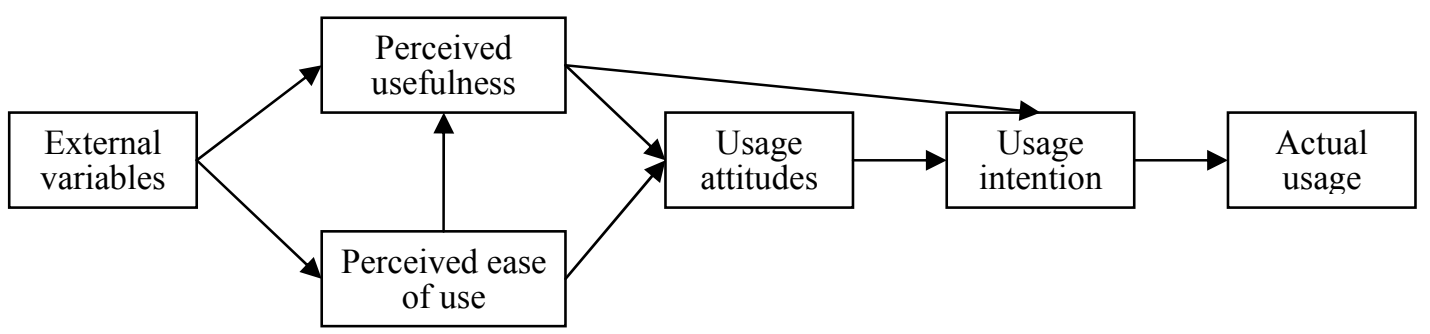

Source: Davis et al. (1989)

Figure 1. TAM framework

TAM's explanation of the individual's acceptance level for technology, usage intention and actual use has been broadly confirmed and applied in academic research and the practical world. In academic research, numerous studies have applied TAM to predict and explain whether system users will accept the introduction of new information technology systems. In the practical world, TAM has been regarded as being a potential diagnostic tool to test the user acceptance of new systems, in order to check and evaluate the addition of new system user acceptance strategies (Hong, Liang and Chang, 2005). Currently, TAM has been used in various fields to explain and confirm the influence of information systems on user attitudes. Davis's (1989) exploration of the student usage of word processing tools in TAM has been confirmed. Lin and Lu (2000) explored the usage of Internet web pages, and the empirical results showed that there is a positive correlation between the perceived ease of use and the perceived usefulness, and that the perceived usefulness also has a positive correlation to usage intentions (Cheng, Lam and Yeung, 2006; Porter and Donthu, 2006; Chu, Huang and Weng, 2008; Wu, Chu and Fang, 2008; Chen, Shang and Liu, 2010; Chen and Liu, 2010). Shih (2004) found that the perceived ease of use has a more significant effect on Internet usage attitudes than the perceived usefulness, and that the perceived ease of use has a positive correlation to the perceived usefulness. Jeyaraj, Rottman and Lacity (2006) pointed out that the important predictive indicators for an individual's acceptance of technology include the perceived usefulness, behavioral intentions, computer experiences, and the support from higher management levels.

\subsection{Research Model and Hypothesis}

The TAM has enough strength that makes it potentially suitable for the adoption of technological innovations. It is a reliable and robust model, with empirical data extensively supporting and validating the theory. The model is supported upon a number of hypotheses derived from the literature. In this study, four constructs were included in the model: usefulness, ease of use, usage of attitude and usage behavioral intention. Based on the relationships between variables postulated by the TAM, the following hypotheses were formulated:

H-1: The box lunch ordering system users' perceived ease of use significantly influences the perceived usefulness.

H-2: The box lunch ordering system users' perceived ease of use significantly influences the usage attitudes.

H-3: The box lunch ordering system users' perceived usefulness significantly influences the usage attitudes.

H-4: The box lunch ordering system users' perceived usefulness significantly influences the usage behavioral intentions.

H-5: The box lunch ordering system users' usage attitudes significantly influences the usage behavioral intentions.

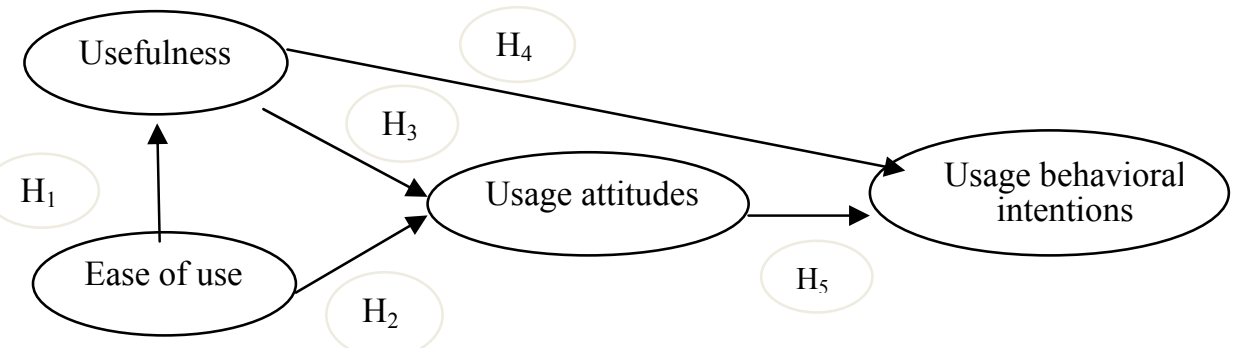

Figure 2. Conceptual model 


\section{Research Method}

\subsection{System Platform}

This study attempted to research the influence on Internet box lunch usage intentions, using Flash CS4 to design a box lunch system, and focusing on university students and office workers during a trial usage period. The system content marked the nutritional content, caloric content, and price of each dish. After the trial, questionnaires were used for the collection of raw data. Figure3 shows the box lunch ordering system screen:

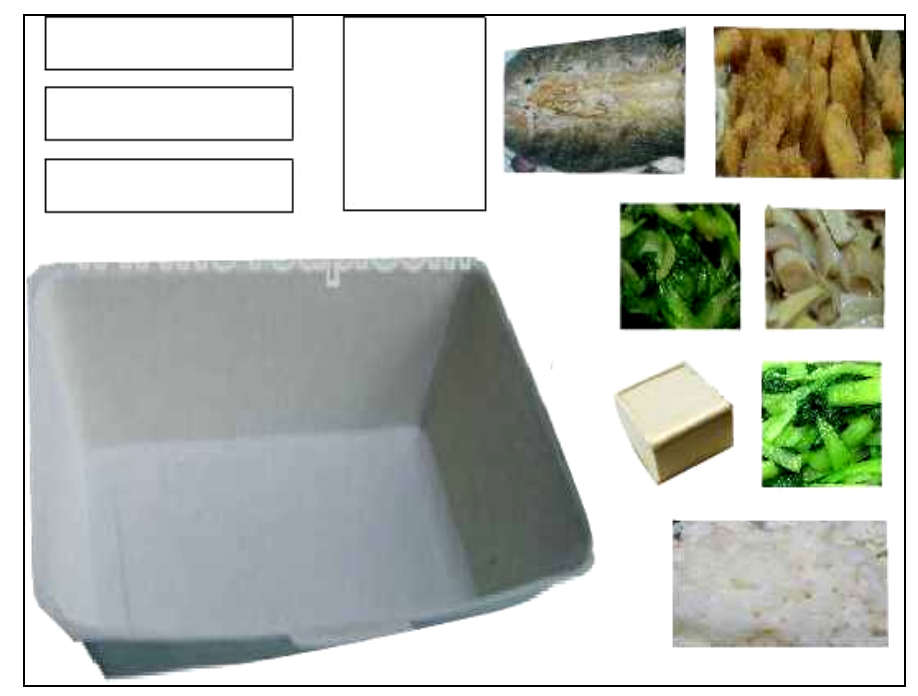

Figure 3. Box lunch system diagram (1)

Figure 4 shows the operational interface for the box lunch ordering system. During usage, the user first moves the cursor to select the dishes:

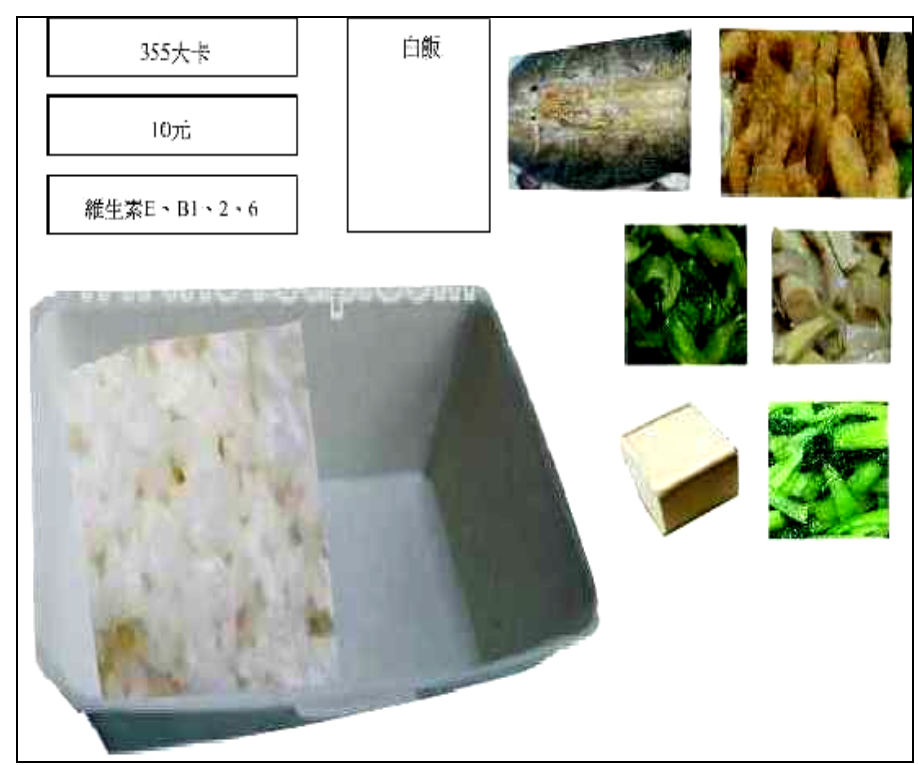

Figure 4. Box lunch system diagram (2)

As shown, the first dish selection is white rice, and after selection, the small box on the top will show the currently selected dish, the price, the caloric content, and the nutritional content. After repeated operations, a result similar to that shown in Figure 5 will appear: 


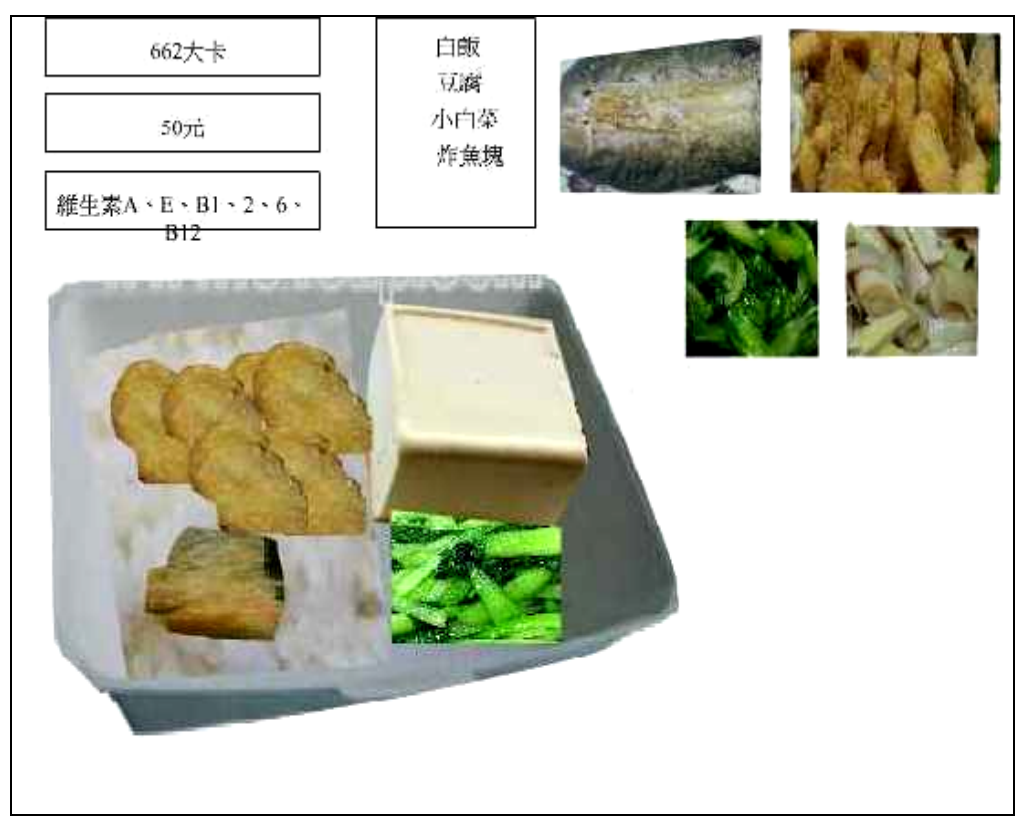

Figure 5. Box lunch system diagram (3)

\subsection{Research Tool}

The measurement tool of this study was based on the structure of the TAM model, in reference to Weng et al. (2009), and used the self-compiled Box Lunch Ordering System and TAM scale as the research tool. The subjects for the pre-test of the items were students at a school in Chiayi. The pre-test subjects first used the system and then completed the pre-test of the items. There were 120 pre-test subjects and 95 valid questionnaires were retrieved, with a valid questionnaire rate of $79 \%$. The scale in this study was divided into five parts: basic demographic background, perceived usefulness, perceived ease of use, usage attitudes, and usage behavioral intentions.

The internal fitness evaluation of the research tool included the reliability, the convergent validity, and the discriminant validity. The descriptive statistical analysis and confirmatory factor analysis of the dimensions are shown in Table 4. The scale used by this study to measure the four dimensions was based on a modification of previous scales proposed by scholars. The scales' Cronbach's alpha was used to assess the internal consistency of the proposed constructs. Table 4 summarizes the loading ranges and $\alpha$ value for each construct identified and used. The Cronbach's $\alpha$ value of the sub-dimensions ranged from 0.79 to 0.91 ; these are greater than 0.7 and thus the constructs were considered reliable.

The factor loading of the measured variables to the latent variables is an index of individual item reliability. The individual item factor loadings are statistically significant if they are all over 0.5 , which conforms to the suggested values by Hair et al. (1998). Regarding the scale reliability evaluation, Huang (2004) pointed out that any individual observed variables with excessively high residual values after the standardization of confirmatory factor analysis, or those with excessively low factor loading, should be deleted. Items with a standardized factor loading of 0.45 should be kept, meaning that the individual observed variable reliability must be greater than 0.20 . Appendix A shows that the factor loadings of the observed variables were all between 0.511 and 0.881 , and the individual reliability of the observed variables (SMC) were between 0.26 and 0.78 , which conformed to suggested values of Hair et al. (1998). Thus, the individual items of this study had sufficient reliability. The individual dimension construct reliability $(\mathrm{CR})$ was between 0.80 and 0.91 , which conformed to the suggested construct reliability of greater than 0.60 proposed by Fornell and Larcker (1981); thus, the scale had good construct reliability.

\subsection{Research Subjects}

This study used purposive sampling to survey online users. The test was divided into two parts. The first part was the box lunch ordering system platform instruction and operations, and the second part was the completion of the research questionnaires. There were 312 subjects and 272 valid questionnaires were retrieved, showing a valid questionnaire rate of $87 \%$. 


\section{Results}

This study applied the TAM on box lunch ordering systems, using the linear structural model to establish the relationships and influences of the ease of use, usefulness, usage attitudes, and usage behavioral intentions. The software package AMOS 7.0 was used to evaluate the model fitness and the relationships between the dimensions.

According to Hair et al. (2006), the linear structural model uses the maximum likelihood estimation to measure the parameters. If the sample is too small, it may result in the inability to converge, and if the sample is too large it will cause the maximum likelihood estimation method to be too sensitive. The goodness of fit may become worse, meaning that the chi-square value will increase with the sample size, resulting in the model being rejected. Thus, it was suggested that the sample size should be between 100 300. This study had 272 valid samples, and maximum likelihood was used to estimate the model.

The linear model constructed in this study is shown in Figure 6. The overall model fitness evaluated the overall fitness between the model and the observed data; if the model's fitness was high then its usability would also be high. Generally, the research fitness indicators use $\chi^{2}$; if it is small, the fitness is good. The overall fit indices are generally evaluated by having a chi-square degree of freedom ratio $\left(\chi^{2} / \mathrm{df}\right)$ value smaller than three, an RMSEA value lower than 0.08, GFI and AGFI values that are greater than 0.90, an NNFI value greater than 0.90 , and a CFI value greater than 0.90 . Table 1 shows the overall fit indices of our model $\left(\chi^{2} / \mathrm{df}=2.262, \mathrm{GFI}=.850\right.$, AGFI $=.819$, RMSEA $=.068$, NNFI $=.901, \mathrm{CFI}=.911$ ). We concluded that our findings had reached an acceptable level and could be used to explain our hypotheses.

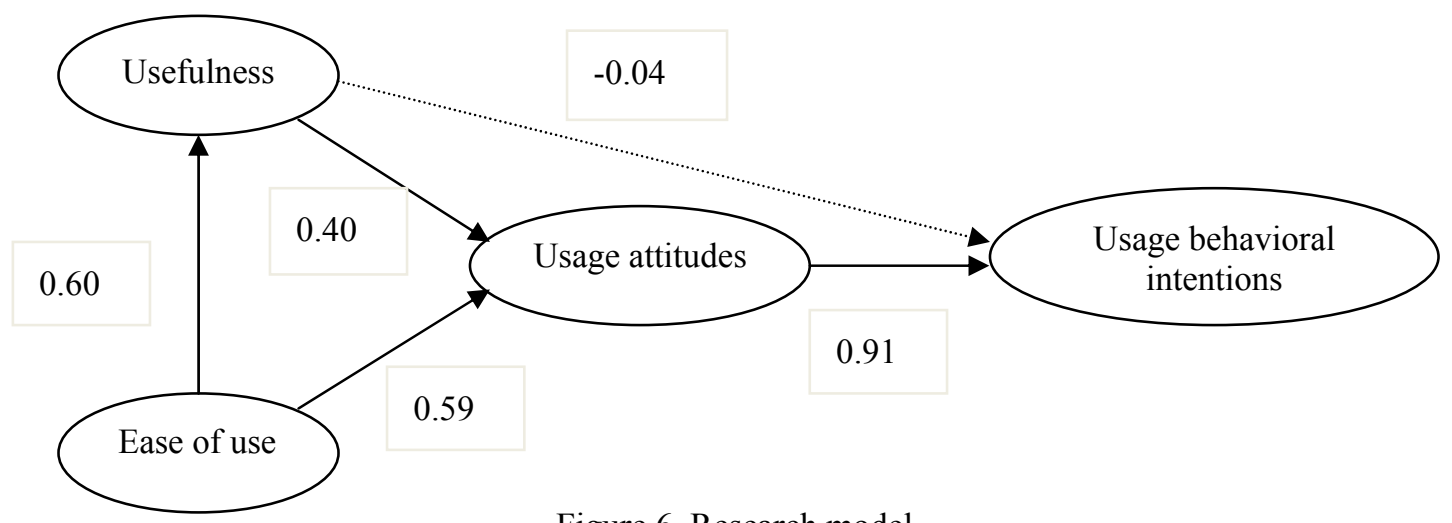

Figure 6. Research model

Table 1. Overall model fitness

\begin{tabular}{lccccccc}
\hline Indicators of fitness & \multicolumn{1}{c}{$\chi^{2}$} & $\chi^{2} / \mathrm{df}$ & GFI & AGFI & RMSEA & NNFI & CFI \\
\hline Suggested value & & $<3.0$ & $>0.9$ & $>0.9$ & $<0.08$ & $>0.9$ & $>0.9$ \\
Research model & $\begin{array}{l}\mathrm{p}>.05 \\
\chi^{2}=560.87\end{array}$ & 2.262 & 0.850 & 0.819 & 0.068 & 0.901 & 0.911 \\
& $\mathrm{P}=0.000$ & & & & & & \\
\hline
\end{tabular}

Table 2. Path and hypothesis evaluation of the structure model

\begin{tabular}{|c|c|c|c|}
\hline \multicolumn{2}{|l|}{ Path } & \multirow{2}{*}{$\begin{array}{c}\text { Structural coefficient } \\
0.60^{* * *}\end{array}$} & \multirow{2}{*}{$\begin{array}{c}\text { Result } \\
\text { supported }\end{array}$} \\
\hline $\mathrm{H}_{1}$ : ease of use & -> usefulness & & \\
\hline $\mathrm{H}_{2}$ : ease of use & -> usage attitudes & $0.59^{* * *}$ & supported \\
\hline $\mathrm{H}_{3}$ : usefulness & -> usage attitudes & $0.40^{* * *}$ & supported \\
\hline $\mathrm{H}_{4}$ : usefulness & -> usage behavioral intentions & -0.04 & rejected \\
\hline \multicolumn{2}{|c|}{$\mathrm{H}_{4}$ : usage attitudes -> usage behavioral intentions } & $0.91^{* * *}$ & supported \\
\hline
\end{tabular}


In the structural model, the box lunch ordering system's ease of use was shown to affect the user's perceived usefulness. The structural coefficient was 0.60 , which was significant, and supported H1. The structural coefficients of the ease of use and the usefulness for usage attitudes were 0.59 and 0.40 , respectively. Ease of use and usefulness had a positive effect on usage attitudes, which showed that $\mathrm{H} 2$ and $\mathrm{H} 3$ conformed to the theoretical expectations and had support from the data. In addition, the ease of use and usefulness had an explanatory power of $79 \%$ for the usage attitudes. The structural coefficient of usage attitudes to usage behavioral intentions was 0.91 , which indicated that usage attitudes had a positive effect on usage behavioral intentions; thus supporting hypothesis 4 . Seen from the overall model, the ease of use, usefulness, and usage attitudes had an explanatory power of $79 \%$ for the usage behavioral intentions (see Table 2, Figure 6).

Table 3 shows the direct, indirect and total effects of significant model constructs. The direct effects of ease of use and usefulness on usage attitudes are 0.59 and 0.40, respectively. Apparently ease of use and usefulness had indirect effects on the usage behavioral intentions through the mediator of the usage attitudes. This showed that the total effect of the box lunch ordering system's ease of use and usefulness on usage behavioral intentions is produced through usage attitudes.

Table 3. Direct, indirect and total effect of significant model constructs

\begin{tabular}{cccc}
\hline & \multicolumn{3}{c}{ Total effect } \\
\hline & Ease of use & Usefulness & Usage attitudes \\
Usefulness & .60 & .00 & .00 \\
Usage attitudes & .83 & .40 & .00 \\
Usage behavioral intentions & .74 & .32 & .91 \\
Usefulness & \multicolumn{3}{c}{ Direct effect } \\
Usage attitudes & .60 & .00 & .00 \\
Usage behavioral intentions & .59 & .40 & .00 \\
& .00 & -.04 & .91 \\
Usage attitudes & .24 & Indirect effect & \\
Usage behavioral intentions & .74 & .00 & .00 \\
\hline
\end{tabular}

\section{Conclusion and Suggestions}

\subsection{Conclusion}

This study explored the influences of technology users' perceived ease of use and perceived usefulness of a box lunch ordering platform on their usage attitudes and usage behavioral intentions. Actual users of a box lunch ordering system were the research subjects, and the linear structure equation model was used to confirm the relationship between the dimensions in the TAM. The results showed that the users' perceived ease of use of the box lunch ordering system platform would significantly influence the perceived usefulness and would indirectly affect usage attitudes through the perceived usefulness, while the perceived usefulness would also directly affect usage attitudes. In the single model, the TAM's usefulness and ease of use are the factors that affect usage attitudes, and the usage attitude is the antecedent variables for the usage behavioral intentions, which is consistent with past researches (Davis et al., 1989; Patrick, 1996; Igbaria and Tan, 1997; Venkatesh and Davis, 2000; Lin and Lu, 2000; Moon and Kim, 2001; Wu, 2001; Chen et al., 2002; Shih, 2004; Yen, 2005; Vijayasarathy, 2004; Shang et al., 2005; Cheng, Lam and Yeung, 2006; Porter and Donthu, 2006; King and He, 2006; Schepers and Wetzels, 2007; Chang, 2007). However, usefulness does not have a significant influence on usage behavioral intentions, which differs from the TAM model. This finding is consistent with Mathieson (1991), Taylor and Todd (1995a, 1995b), and Ren, Lu and Liu (2009). Hong et al. (2005) suggested that the variables and causal relationships in different theoretical models are different, and since each study explores different issues and confirmation subjects or uses different theories, it will result in inconsistencies among the research results. In addition, models that are more complex do not have better explanatory power, but a TAM with a more simplistic model structure has the advantages of richness and conciseness (Ren, Lu and Liu, 2009). 


\subsection{Suggestions}

The model in this study verified that the perceived usefulness and perceived ease of use are important factors in user acceptance behavior, and that they have both a direct and indirect positive effect on consumer usage attitudes and behavioral intentions. At the same time, since usage attitude plays an intermediary role in user acceptance behavior, the elevation of the system usage interface richness and operational procedure smoothness should enhance positive attitudes toward the perceived usefulness of the system, and in turn enhance the usage behavioral intentions.

For future studies, as the selection of external variables affects the system's perceived ease of use, perceived usefulness, usage attitudes, and usage behavioral intentions, the external variables should consider the visual and entertainment character and the operational contexts of box lunch ordering systems, as well as external factors such as personal usage experiences and the personal traits of users, in order to enhance the model's explanatory power.

\subsection{Research Limitations}

Due to research budget and manpower limitations, the scope of this research was limited to Chiayi County and City; therefore, the research results cannot be generalized to other areas. Since the research subjects were people who are had a basic ability in using computers and related equipment, its coverage cannot represent consumers of all age groups.

\section{References}

Anand Jeyaraj, Joseph W. R., \& Mary C. L. (2006). A review of predictors, linkages, and biases in IT innovation adoption research. Journal of Information Technology, 21, 1-23. http://dx.doi.org/10.1057/palgrave.jit.2000056

Bingzhang C., \& Hongbin L. (2010). Integrating service quality and TAM perspectives to explore factors that affect consumer online trust and purchase intention. Journal of Customer Satisfaction, 6(1), 1-32.

Chang C. H. (2011). Modern Psychology. Taipei: Dong Hua Books.

Chang C. M. (2007). Using technology acceptance model to confirm intentions to participate in table tennis. Journal of Management Practices and Principles, 1(2), 76-88.

Chen, L. D., Gillenson, M. L., \& Sherrell, D. L. (2002). Enticing online consumers: an extended technology $\begin{array}{llll}\text { acceptance perspective. Information and Management, 39(8), } & \text { 705-719. }\end{array}$ http://dx.doi.org/10.1016/S0378-7206(01)00127-6

Cheng, T. C. E., Lam D. Y. C., \& Yeung A. C. L. (2006). Adoption of Internet Banking: An Empirical Study in Hong Kong. Decision Support Systems, 42, 1558-1572. http://dx.doi.org/10.1016/j.dss.2006.01.002

Chia-Lin H., Cou-Chen W., Mu-Chen C., \& Kuo-Chien C. (2012). Formation of E-satisfaction and E-loyalty: An Extension of Technology Acceptance Model with Perceived Quality and Flow Experience. Journal of Quality, 19, 61-83.

Chu et al. (2008). Using technology acceptance model to explore usage intention of real-time transportation information system. Journal of e- Business, 10(1), 173-200.

Davis F. D. (1989). Perceived usefulness, perceived ease of use and user acceptance of information technology. MIS Quarterly, 13, 319-340. http://dx.doi.org/10.2307/249008

Fangming H., Jinbao Y., \& Fusheng X. (2005). Development of adolescent life indicators of pain. Journal of National Taiwan Normal University: Education Type, 50(2), 97-119.

Fornell and Larcker. (1981). Evaluating structural equation models with unobservable variables and measurement error. Journal of Marketing Research, 18(1), 39-50. http://dx.doi.org/10.2307/3151312

Freshnet. (2009). Nostalgia for 60 years, rise of railway box lunches. Retrieved from http://www.freshnet.tw/newspage.php?articleid=1844

Hair, J. F. Jr., Anderson, R. E., Tatham, R. L., \& Black, W. C. (1998). Multivariate data analysis (5th ed.). Upper Saddle River, NJ: Prentice-Hall.

Huang F. M. (2004). Statistical Methodology Structured Equation Models in Social Sciences. Taipei: Wu Nan Books. 
Igbaria, M., \& Tan M. (1997). The Consequence of Information Technology Acceptance Subsequent Individual Performance. Information and
http://dx.doi.org/10.1016/S0378-7206(97)00006-2

Lin, J. C. C., \& Lu H. (2000). Toward an understanding of the behavioral intention to use a web site. International Journal of Information Management, 20(3), 197-208. http://dx.doi.org/10.1016/S0268-4012(00)00005-0

Mathieson K. (1991). Predicting user intention: comparing the technology acceptance model with theory of planned behavior. Information Systems Research, 2(3), 173-191. http://dx.doi.org/10.1287/isre.2.3.173

Moon and Kim. (2001). Extending the TAM for a World-Wide-Web context. Information \& Management, 38, 217-230. http://dx.doi.org/10.1016/S0378-7206(00)00061-6

Ning-Yuean L., \& Jean-May T. (1982). Studies on Some Problems of Nutrition and Sanitation in Taiwan Area-I: A Study on the Sanitation, Safety, Packaging and Nutritional Content of Commercial Lunch Boxes. Nutritional Sciences Journal, 7(1\&2), 15-28.

Patrick and Chau. (1996). An empirical investigation on factors affecting the acceptance of CASE by systems developers. Information \& Management, 30, 269-280. http://dx.doi.org/10.1016/S0378-7206(96)01074-9

Porter and Donthu. (2006). Using the technology acceptance model to explain how attitudes determine Internet usage: the role of perceived access barriers and demographics. Journal of Business Research, 59, 999-1007. http://dx.doi.org/10.1016/j.jbusres.2006.06.003

Schepers and Wetzels. (2007). A meta-analysis of the technology acceptance model: investigating subjective norm and moderation effects. Information \& Management, 44(1), 90-103. http://dx.doi.org/10.1016/j.im.2006.10.007

Shang, R. A., Chen, Y. C., \& Shen, L. (2005). Extrinsic versus intrinsic motivations for consumers to shop on-line. Information \& Management, 42, 401-413. http://dx.doi.org/10.1016/j.im.2004.01.009

Shih H. P. (2004). An empirical study on predicting user acceptance of e-shopping on the web. Information \& Management, 41(3), 351-368. http://dx.doi.org/10.1016/S0378-7206(03)00079-X

Shin-Yuan H., Ting-Peng L., \& Chia-Ming C. (2005). A meta-analysis of empirical research using TAM. Journal of Information Management, 12(4), 211-234.

Shirley T., \& Peter. A. T. (1995a). Understanding information technology usage: a test of competing models. Information Systems Research, 6(2), 144-176. http://dx.doi.org/10.1287/isre.6.2.144

Shirley T., \& Peter. A. T. (1995b). Assessing IT usage: the role of prior experience. MIS Quarterly, 19(4), 561-570. http://dx.doi.org/10.2307/249633

Szajna B. (1996). Empirical evaluation of the revised technologyacceptance model. Management Science, 42(1), 85-92. http://dx.doi.org/10.1287/mnsc.42.1.85

Ting-Sheng W., Tsai-Mu S., Tsung-Chih C., \& Shiou-Ying C. (2009). Establishing an orchid management information system and analysis of use intention. 2009 International Conference on Business And Information, Malaysia.

Tsai Y. L. (2011). New opportunities for the Taiwan food industry in the post-ECFA era. Taiwan Economic Research Monthly, 34(6), 43-51.

Venkatesh V., \& Davis, F. D. (2000a). A theoretical extension of the technology acceptance model: four $\begin{array}{lllll}\text { longitudinal field } & \text { studies. }\end{array}$ http://dx.doi.org/10.1287/mnsc.46.2.186.11926

Venkatesh V., \& Davis, F. D. (2000b). A model of the antecedents of perceived ease of use: development and test. Decision Sciences, 27(3), 451-481. http://dx.doi.org/10.1111/j.1540-5915.1996.tb01822.x

Vijayasarathy L. R. (2004). Predicting consumer intentions to use on-line shopping: the case for an augmented technology acceptance model. Information \& Management, 41(6), 747-762. http://dx.doi.org/10.1016/j.im.2003.08.011

William J., Tim L., \& Po-Ting L. (2009). Integrated analysis of technology acceptance behavioral model: comparison between three main models. MIS Review, 15(1), 101-138.

William R. K., \& Jun H. (2006). A meta-analysis of the technology acceptance model. Information and Management, 43(6), 740-755. http://dx.doi.org/10.1016/j.im.2006.05.003 
Wu T. (2001). Analysis of Modified TAM Theory in Online Gaming Behavioral Factors. Graduate Institute of Resource Management, Management College, National Defense University.

Wuya X., Zhu Su Y., \& Wen-Chang F. (2008). Empirical research on online shopping trust and technology acceptance model. Journal of Information Management, 15(1), 123-152.

Ya-Hsing W., Su-Yueh C., \& Wen-Chang F. (2008). An Empirical Study of Trust and TAM-An Example of Online Shopping. Journal of Information Management, 15(1), 132-152.

Yen H. J. R. (2005). An attribute-based model of quality satisfaction for internet self-service technology. The Service Industries Journal, 25(5), 641-659. http://dx.doi.org/10.1080/02642060500100833

Yu-Chen C., Rong-An S., \& Wey-Ting L. (2010). An Analysis of the Behavioral Intention to Accept e-Business Systems based on TAM and TTF: The effects of organizational learning of organizationally alienated employees. Journal of Information Management, 17(4), 139-169.

\section{Appendix}

Appendix A. Composite reliability analysis of the descriptive statistics of the variables and measurement dimensions

\begin{tabular}{|c|c|c|c|c|c|}
\hline Dimension & Indicator & SFL & SMC & $\mathrm{CR}$ & AVE \\
\hline \multirow{5}{*}{$\begin{array}{l}\text { Ease of use } \\
\qquad(\alpha=.845)\end{array}$} & PE3 The system content conforms to needs & .700 & .490 & \multirow{5}{*}{.845} & \multirow{5}{*}{.529} \\
\hline & PE4 The system content is new and fun & .801 & .642 & & \\
\hline & PE5 The system content is attractive & .881 & .776 & & \\
\hline & PE6 The contents of the dishes are easy to search for & .662 & .438 & & \\
\hline & PE7 The reality of dishes in the system & .548 & .300 & & \\
\hline \multirow{5}{*}{$\begin{array}{l}\text { Usefulness } \\
(\alpha=.791)\end{array}$} & PU3 The diversity of dishes in the system & .511 & .261 & \multirow{5}{*}{.797} & \multirow{5}{*}{.448} \\
\hline & PU4 The economical character of dishes in the system & .572 & .327 & & \\
\hline & PU5 The nutrition of dishes in the system & .788 & .621 & & \\
\hline & PU6 The healthfulness of dishes in the system & .822 & 676 & & \\
\hline & PU7 The dishes in the system care about the customers & .597 & .356 & & \\
\hline \multirow{6}{*}{$\begin{array}{l}\text { Usage } \\
\text { attitudes } \\
(\alpha=.843)\end{array}$} & AT1 I think it is smart to use this system & .715 & .511 & \multirow{6}{*}{.843} & \multirow{6}{*}{.475} \\
\hline & AT3 I think this system is beneficial to my health & 636 & .404 & & \\
\hline & AT4 I think this system is beneficial to my budget & .602 & .362 & & \\
\hline & AT5 I think this system is concerned about the client & 695 & .483 & & \\
\hline & AT6 I think this system is what I need & .791 & .626 & & \\
\hline & AT8 I think this system has enhanced good services & 680 & .462 & & \\
\hline \multirow{8}{*}{$\begin{array}{c}\text { Usage } \\
\text { behavioral } \\
\text { intentions } \\
(\alpha=.911)\end{array}$} & BI1 If I need to order meals, I will want to use this system & .730 & .533 & \multirow{8}{*}{.913} & \multirow{8}{*}{.567} \\
\hline & BI2 If I need to order meals, I will certainly use this system & .740 & .548 & & \\
\hline & $\begin{array}{l}\text { BI3 When there are multiple systems to choose from, I will } \\
\text { still use this system as a priority }\end{array}$ & .791 & 626 & & \\
\hline & $\begin{array}{l}\text { BI4 I will introduce this system to my friends and relatives } \\
\text { so they can use it }\end{array}$ & .793 & 629 & & \\
\hline & $\begin{array}{l}\text { BI6 This system has increased my frequency of buying box } \\
\text { lunches }\end{array}$ & 692 & .479 & & \\
\hline & $\begin{array}{l}\text { BI7 This system has certainly provided me with a } \\
\text { convenient purchasing method }\end{array}$ & .742 & .551 & & \\
\hline & BI8 I will use this system again next time & .817 & .667 & & \\
\hline & $\begin{array}{l}\text { BI9 On the whole I have a high degree of usage intention for } \\
\text { this system }\end{array}$ & .711 & .506 & & \\
\hline
\end{tabular}


Appendix B. Correlation coefficient matrix for the dimensions (AVE method)

\begin{tabular}{lccccc}
\hline \multirow{2}{*}{ Dimension } & \multicolumn{5}{c}{ Correlation coefficients } \\
\cline { 2 - 5 } & Ease of use & Usefulness & $\begin{array}{l}\text { Usage } \\
\text { attitudes }\end{array}$ & $\begin{array}{l}\text { Usage behavioral } \\
\text { intentions }\end{array}$ & AVE \\
\hline Ease of use $^{1}$ & $\mathbf{. 7 2 7 ^ { 1 }}$ & & & & 0.529 \\
Usefulness & .132 & $\mathbf{. 6 6 9}$ & & 0.448 \\
Usage attitudes & .192 & .184 & $\mathbf{. 5 1 0}$ & & 0.475 \\
Usage behavioral intentions & .184 & .177 & .249 & $\mathbf{. 5 5 3}$ & 0.567 \\
\hline
\end{tabular}

Note 1: The values in the diagonals are the square root of the average variance extracted (AVE) of this latent variable. The variable should be greater than the non-diagonal line values 